\title{
A model-data comparison of European temperatures in the Eemian interglacial
}

\author{
Frank Kaspar, ${ }^{1,2}$ Norbert Kühl, ${ }^{3}$ Ulrich Cubasch, ${ }^{2}$ and Thomas Litt ${ }^{3}$ \\ Received 17 January 2005; revised 21 March 2005; accepted 2 May 2005; published 11 June 2005.
}

[1] We present a comparison of reconstructed and simulated January and July temperatures in Europe for a time slice $(\sim 125 \mathrm{kyr}$ BP $)$ within the last interglacial (Eemian, $\sim 127-116$ kyr BP). The reconstructions, based on pollen and plant macrofossils, were performed on 48 European sites using a method based on probability density functions ( $p d f$-method). The reconstructed most probable climate values were compared with a global climate simulation which was realized with a coupled oceanatmosphere general circulation model. Orbital parameters and greenhouse gas concentrations have been adapted to conditions at $125 \mathrm{kyr}$ BP. Reconstructions and simulation are concordant in showing higher temperatures than today over most parts of Europe in summer and in revealing a west-east-gradient in winter temperature differences with increasing anomalies toward eastern Europe. The results indicate that differences in the orbital parameters are sufficient to explain the reconstructed Eemian temperature patterns. Citation: Kaspar, F., N. Kühl, U. Cubasch, and T. Litt (2005), A model-data comparison of European temperatures in the Eemian interglacial, Geophys. Res. Lett., 32, L11703, doi:10.1029/ 2005 GL022456.

\section{Introduction}

[2] Assessing future climate evolution is a major challenge for model simulations which provide scenarios of possible future climate change. Models, however, need to be validated to assure that they are in fact able to reproduce observed climate change. Many projections of climate change are large compared to changes in climate during the last centuries. Simulations of past interglacial climates allow to evaluate how models respond to stronger changes in forcing. Interglacials, such as the Eemian $(\sim 127-116 \mathrm{kyr}$ BP), are defined as warm intervals during which global climate reaches at least the preindustrial level of warmth [Kukla et al., 2002]. Interglacial-glacial-cycles during the last 500,000 years are believed to be driven by changes in insolation as a result of variations in Earth's orbit around the Sun [Berger and Loutre, 2002], although change in insolation is questioned to be strong enough to explain the climate variability over interglacial-glacial-cycles [Wunsch, 2004].

[3] Coupled ocean atmosphere general circulation models (OA-GCMs) are tools to simulate climate under different boundary conditions and its response to their changes.

\footnotetext{
${ }^{1}$ Model and Data Group, Max Planck Institute for Meteorology, Hamburg, Germany.

${ }^{2}$ Institut für Meteorologie, Freie Universität Berlin, Berlin, Germany.

${ }^{3}$ Institute for Palaeontology, University of Bonn, Bonn, Germany.

Compared to the wide range of different models used for the analysis of the climate system, GCMs have the most complex representation of the atmospheric physical processes. We have chosen the ECHO-G model as a state-ofthe-art OA-GCM to simulate the climatic conditions at 125 kyr BP by adapting the orbital parameters and greenhouse gas concentrations.

[4] For terrestrial palaeoclimate reconstructions, the use of botanical fossils is well-established, because vegetation is in close relation to climate. Mainly pollen can be found in large numbers in suitable sediments, and macro remains add valuable information for important climate indicator species. For the reconstructions, recently developed botanical climatological transfer functions [Kühl et al., 2002] were used.

[5] In the following, reconstructions are shown of the early part of the Eemian which is biostratigraphically recognizable over whole Europe. The reconstructed temperature patterns are compared with the simulations of the ocean-atmosphere model.

\section{Material and Methods}

\subsection{Eemian Sites With Palaeobotanical Records}

[6] Eemian sites are very common in Europe. Eemian pollen diagrams show a very uniform vegetation succession throughout Europe, hence allowing to define and to correlate pollen assemblage zones (PAZ) [Menke and Tynni, 1984]. Plant migration may have caused a somewhat later beginning of each PAZ in the north compared to the south. Nevertheless, we expect the lag to be short enough to allow the assumption that the main part of a PAZ is isochronous, provided that the zone lasted for at least several hundred years. This is the case for the distinct Corylus-phase, pollen zone IVa after Menke and Tynni [1984], which represents the early Eemian around $125 \mathrm{kyr}$ BP. By counting the varves, Müller [1974] showed that the zone lasted $\sim 1150$ years. We selected high quality sites for the reconstructions, which are preferably long records and records that give information about macro remains. In addition, the number of pollen counted per spectrum should be high (preferably at least 500 pollen grains). Only high pollen counts assure that climate sensitive taxa with low pollen dispersal and therefore low representation in pollen diagrams are detected. Based on these criteria, 48 sites were chosen to reconstruct the January/July temperatures of the early Eemian, 16 of these sites contain both pollen and macro remains ${ }^{1}$.

\footnotetext{
${ }^{1}$ Auxiliary material is available at $\mathrm{ftp}: / / \mathrm{ftp}$.agu.org/apend/gl/ 2005 GL022456.
} 
Table 1. Boundary Conditions of the Simulations

\begin{tabular}{lcccccc}
\hline & & \multicolumn{4}{c}{} & Angle of \\
& Eccentricity & Obliquity $\left[{ }^{\circ}\right]$ & Perihelion $\left[{ }^{\circ}\right]$ & $\mathrm{CO}_{2}[\mathrm{ppmv}]$ & $\mathrm{CH}_{4}[\mathrm{ppmv}]$ & $\mathrm{N}_{2} \mathrm{O}[\mathrm{ppbv}]$ \\
\hline $125 \mathrm{kyr} \mathrm{BP}$ & 0.0400 & 23.79 & 127.3 & 270 & 630 & 160 \\
Preindustrial & 0.0167 & 23.44 & 282.7 & 280 & 700 & 265 \\
\hline
\end{tabular}

\subsection{Temperature Reconstruction}

[7] For the reconstructions based on botanical proxy data, we applied the newly established $p d f$-method [Kühl et al., 2002] which is based on probability density functions $(p d f \mathrm{~s})$. The $p d f$-method describes the relationship between occurrence of plants and climatic parameters by probability density functions, expressed by conditional $p d f \mathrm{~s}$ of the type $p d f(C \mid a)$ with $C=$ climate parameter(s) and $a=$ taxon present. A normal distribution appears to be sufficient as estimator function for the $p d f \mathrm{~s}$ of the selected taxa [Kühl et al., 2002]. The pdfs of the individual taxa are combined by multiplication, with the mean $\mu$ of the resulting normal distribution being interpreted as reconstructed most probable climate and $\sigma$ as uncertainty range.

[8] The combination method includes a selection procedure which avoids a biased uncertainty range that could be caused by the multiplication of very similar $p d f \mathrm{~s}$. The $p d f$-method is based on presence and absence of species and consequently relies on the climate dependency of individual taxa rather than on the composition of pollen spectra in relation to climate (see the so-called modern analogue technique [Guiot, 1990]). This makes the method robust to common problems that challenge transfer functions, in particular the fact that most Eemian plant communities seem to be without analogous modern counterparts [Kühl and Litt, 2003]. One reason is the human impact which heavily altered vegetation, which was the case particularly in Europe over the last thousands of years. Moreover, not only pollen, but also macro remains can be incorporated in the reconstruction. This improves the information obtainable from the fossil record, because macro remains can add taxa that are not present in the pollen record and usually allow the determination of species, while pollen often only reveals a higher taxonomic level, e.g. the genus.

[9] The $p d f$-method combines the strengths of an indicator species method with additional advantages: the complete distribution areas rather than individuals living at a taxon's distribution limit determine the reconstruction result. Hence, specific conditions (e.g. microclimate) at the distribution limits of the taxa are not important. In contrast to the mutual climatic range method [e.g., Sinka and Atkinson, 1999], the $p d f$-method combines $p d f \mathrm{~s}$ by multiplication rather than using an overlap of climate spaces which denotes for its characteristic that the climate limit of an individual taxon is not decisive for the reconstruction. Competition heavily influences the existence at the distribution limits where fitness of a species is reduced compared to areas with optimum conditions. Estimating the taxon-climate relationship by $p d f \mathrm{~s}$ as well as combining them by multiplication assure that the reconstruction method is robust to effects of competition. Kühl and Litt [2003] and Kühl et al. [2002] discuss differences to other methods.

\subsection{The Model and the Boundary Conditions of the Eemian Simulation}

[10] The ECHO-G model [Legutke and Voss, 1999] consists of the ECHAM4 atmosphere model coupled to the HOPE-G ocean model. The atmospheric component has a horizontal resolution of T30 $\left(\sim 3.75^{\circ}\right)$ and 19 vertical levels with the highest level at $10 \mathrm{hPa}$. The ocean model operates on a T42 grid $\left(\sim 2.8^{\circ}\right)$ with a gradual meridional refinement toward the equator to $0.5^{\circ}$. Both components are coupled with a flux correction. The model shows an overall good skill in simulating today's climatology and interannual variability [Min et al., 2005]. A detailed evaluation of OA-GCMs is provided by McAvaney et al. [2001].

[11] The simulations are performed as equilibrium experiments with constant boundary conditions. For the simulation of the Eemian climate, orbital parameters and greenhouse gas concentrations have been set to values of $125 \mathrm{kyr}$ BP. Orbital parameters are calculated according to Berger [1978]. The combined effect of greater obliquity and eccentricity, together with the fact that perihelion occurred in Northern Hemisphere summer caused an amplification of the seasonal cycle of insolation. Summer insolation in the Northern Hemisphere was significantly higher than today (see Figure 1 in the auxiliary material). Greenhouse gas concentrations $\left(\mathrm{CO}_{2}, \mathrm{CH}_{4}, \mathrm{~N}_{2} \mathrm{O}\right)$ are based on Vostok ice cores [Petit et al., 1999; Sowers, 2001]. The model's default values are retained for all the remaining boundary conditions, i.e. present-day conditions are used. A simulation with preindustrial conditions is used for comparison. Table 1 shows all parameters. Due to the small differences in the greenhouse gas concentrations, the observed differences in simulated climate can be attributed to orbitally induced insolation change.

\section{Results}

\subsection{Results of the Palaeoclimatic Reconstruction}

[12] Figures 1 and 2 show the reconstructed most probable climate of the Corylus-phase as difference to observed present-day temperatures [New et al., 1999]. For reason of visualisation and comparison, the two-dimensional $p d f s$ are split into January and July temperatures. The local values of the uncertainty ranges vary, being larger in higher latitudes where cold resistant taxa dominate Quantification of standard deviations can be found in Table 2 of the auxiliary material. In the Alps, uncertainties are caused by the strong relief with a high variance in exposition.

[13] Reconstructed July temperatures differ between coast and inland. Compared to the inland, relatively low summer temperatures are reconstructed for the coast with most probable July values often below $17^{\circ} \mathrm{C}$. These reconstruction results go back to oceanic species, e.g. Ilex aquifolium occurs in the early Eemian at some sites close to the coast, while it did not occur in most parts of central Europe during that time. In contrast, macrofossils of sub- 


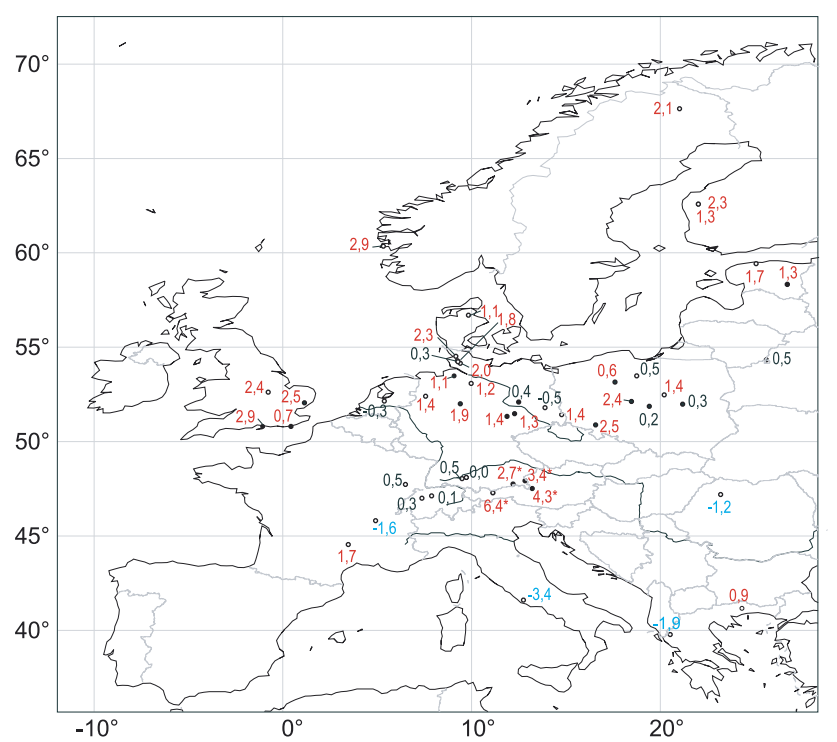

Figure 1. Reconstructed most probable July temperatures of the Corylus-phase as anomalies from observed present day temperatures $[\mathrm{K}]$. Filled circles denote sites from which in addition to pollen, plant macrofossils were used for the temperature reconstructions. ${ }^{*}$ Sites with an altitude difference of more than 200 meters between the reconstruction site and the corresponding height of the climate dataset which may account for somewhat too high values.

continental or continental species are found in the inland. Examples are Acer tataricum at Grabschütz (Saxony, Germany), Neumark-Nord (Saxony-Anhalt, Germany) and Imbramovice (Poland) and Tilia tomentosa at Wallensen (Lower Saxony, Germany). These taxa show an occurrence far more north during the early phase of the Eemian than today. They cause the reconstruction of quite warm summer conditions in central Europe, with temperatures about 1$2^{\circ} \mathrm{C}$ higher than today at most sites north of the Alps. For most locations in southern Europe, colder conditions than today are reconstructed (Italy, Southern France, Greece, Romania).

[14] In the absolute January temperatures a significant gradient occurs between the coastal area and the inner regions of the continent. Relatively high values $\left(>1{ }^{\circ} \mathrm{C}\right)$ occur mainly in the coastal region from Great Britain to Scandinavia. A similar, even more pronounced gradient exists today. Today, the reason for the warm coastal regions is the heat transport by the North Atlantic current, which leads to relatively mild winters compared to other regions on the same latitude. The distance to the ocean is responsible for the observed gradient into the continent. Compared to today, somewhat lower January temperatures are reconstructed for western Europe (France, UK), whereas increasing values can be noted toward North-East-Europe, with differences larger than $6^{\circ} \mathrm{C}$ in the region of Finland (Figure 1). The low values on the British island may be biased because some taxa that exist in Great Britain are close to their north-western distribution limit and the climate there may therefore not correspond to the maximum of the $p d f \mathrm{~s}$ (climate|taxon). The results give a differentiated picture of Eemian temperatures over Europe and emphasize that statements which characterize the Eemian as overall warmer than today are too simplistic.

\subsection{Model Results}

[15] After approximately 1000 simulated years, the simulations of the Eemian and the preindustrial climate became stable, i.e. quasi-stationary with respect to oceanic overturning circulation and sea ice extent. For the analysis we calculated the mean climate of an arbitrarily selected 50 years interval starting 1200 years after the beginning of both simulations. Selecting different periods does not change the results. The following description of general features focuses on differences between the Eemian and the preindustrial climate on the Northern Hemisphere.

[16] The model responds with a slightly higher global mean temperature in the Eemian than in the preindustrial simulation. The summer $2-\mathrm{m}$ temperature is significantly higher in particular over the continents. Anomalies greater than $+4^{\circ} \mathrm{C}$ are simulated over large areas of Asia. A belt with lower temperatures occurs at around $20^{\circ} \mathrm{N}$ over Africa and Asia. This cooling is related to increased precipitation caused by increased eastward advection of moisture from the Atlantic and Indic Ocean into these regions due to stronger westerly winds. The winter temperatures are lower over the continents with the exception of the area between eastern Europe and Siberia, where higher temperatures prevail. In general, a greater seasonality of the continental temperatures is simulated, which is consistent with the stronger seasonality in the Eemian insolation. Higher winter temperatures occur in the Arctic sea and the eastern part of the Pacific. Reduced sea ice depth occurs in the entire Arctic sea in summer and winter. However, in winter most areas of the Arctic sea are completely covered with sea ice in both simulations except for the region of the Barents Sea, where the sea ice coverage is $20 \%$ lower in the Eemian simulation. Lower average winter sea level pressure occurs over the Atlantic at $70^{\circ} \mathrm{N}$ north of the British Islands and Scandinavia caused by an expansion of the Icelandic low pressure area into this region. This leads to stronger westerly winds

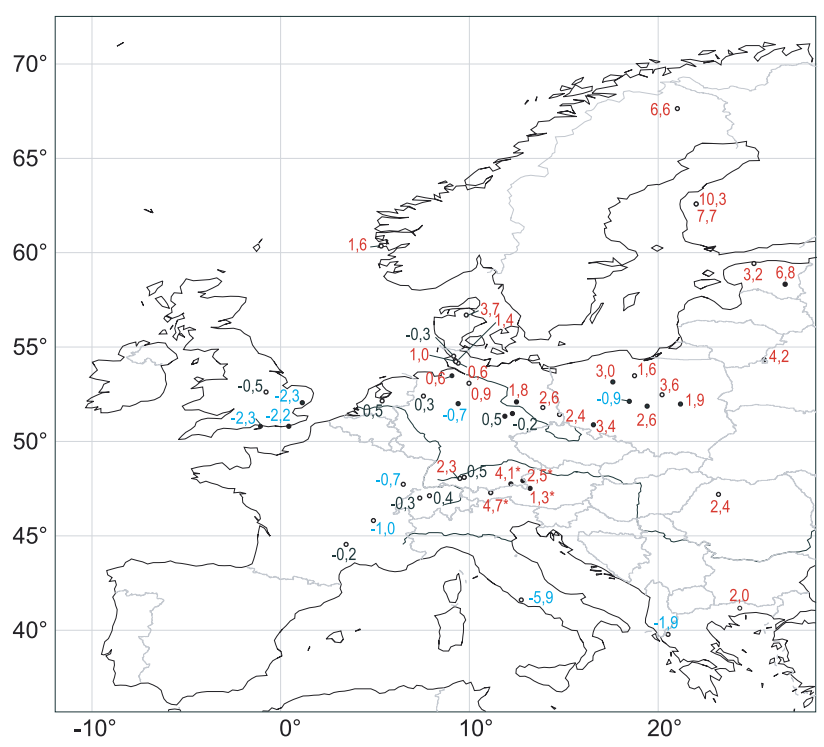

Figure 2. Same as Figure 1, but for January. 
at $60^{\circ} \mathrm{N}$ and increased transport of warm Atlantic air into northern Europe.

\section{Comparison of Reconstructed and Simulated European Temperature Differences}

[17] In the domain of our temperature reconstructions the model simulates an almost homogenous increase of approx. $+2^{\circ} \mathrm{C}$ in July temperatures (Figure 3 ). The increase is less distinct in the region of the Baltic Sea where it is in the order of $+1^{\circ} \mathrm{C}$. Due to the coarse spatial representation of the continental boundaries the model treats these areas as part of the ocean (Figure 3). On the land areas the model simulates a uniform temperature increase. This is mainly a result of the higher summer insolation. The reconstructions agree with the simulations by indicating higher Eemian July temperatures at the majority of the locations with some exceptions in southern Europe. Except for this region the general pattern of the July temperatures is consistent between model and reconstruction.

[18] For January, a gradient in the simulated temperature differences is visible in the region of the reconstructions (Figure 4). The temperatures in western Europe (Spain, France) are similar in the Eemian and the preindustrial simulation. Increasing temperature differences between both simulations occur in the north-east direction toward Scandinavia. In the region of Finland, the differences are in the order of $+3{ }^{\circ} \mathrm{C}$. Again, the general pattern is consistent with the results of the reconstruction, and model and reconstructions only differ in the magnitude of deviation between Eemian and today's climate. In western Europe, the reconstructed differences are more negative than the simulated values, whereas in the direction toward Scandinavia the positive deviations reach larger values.

[19] The overall similarity in the pattern allows the conclusion that the same processes are responsible for the spatial distribution in the model and in the estimates from the paleoecological data. The winter temperature anomalies can not be explained by insolation change directly, because the winter insolation in the high northern latitudes was lower in the Eemian than today. Therefore it can only explain the western European temperature differences. For

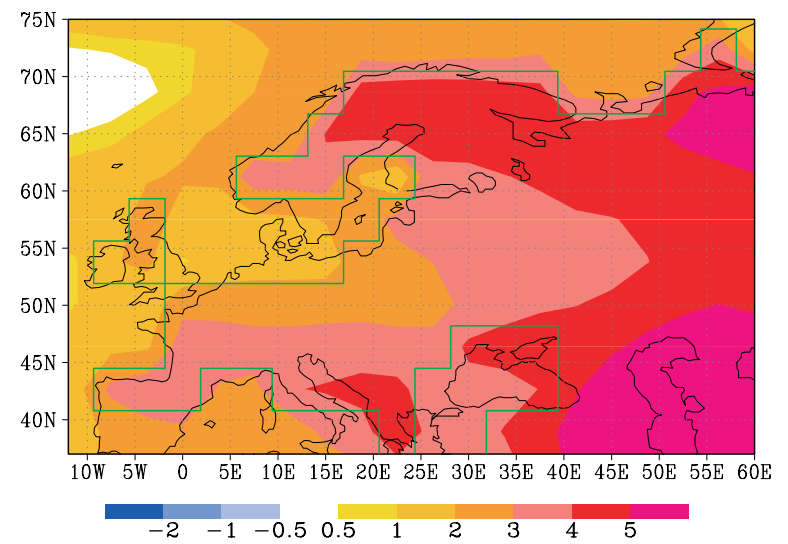

Figure 3. Simulated July temperature anomalies $[\mathrm{K}]$ : Eemian at $125 \mathrm{kyr}$ BP minus preindustrial, averaged over a 50 year interval. Green lines indicate the model's land mask.

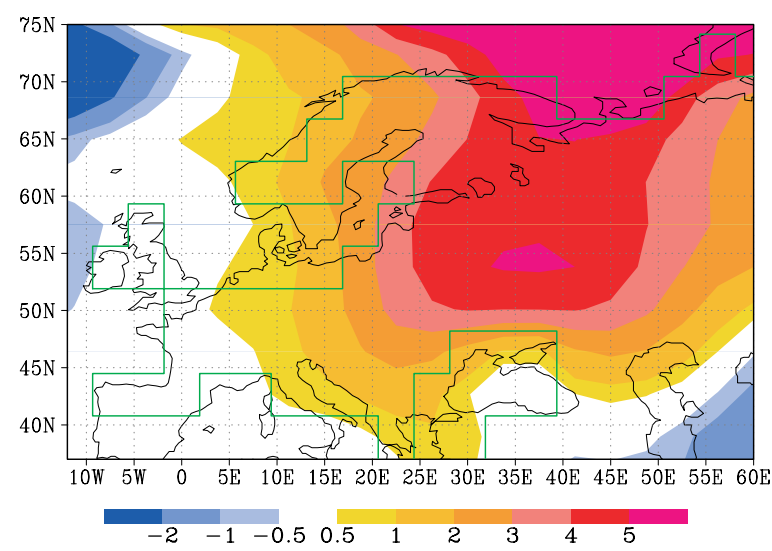

Figure 4. Same as Figure 3, but for January.

the increasingly positive differences toward Scandinavia a combination of effects is responsible: On the one hand increased westerlies transport more oceanic heat into this region. On the other hand the winter sea ice coverage in the Barents Sea is significantly reduced. This causes a strong reduction in the surface albedo, which leads to significantly increased regional temperatures. The decreased sea ice coverage is mainly caused by the increase in summer insolation, which is most distinct in the high northern latitudes. The resulting decrease of sea ice in summer is not compensated by the reduced winter insolation. As the climate model does not contain a dynamic vegetation, the results indicate that changes in the atmosphere-ocean dynamics alone are sufficient to explain the reconstructed European temperature patterns.

\section{Conclusions}

[20] The simulated and reconstructed January and July temperatures are in good agreement for the early Eemian in Europe. Obviously, the model is able to simulate a realistic Eemian climate at least for the European area. Orbitally induced changes in insolation as forcing factor are sufficient to explain the observed temperature patterns. Higher Eemian summer temperatures are directly connected to increased Eemian summer insolation. Winter temperature anomalies are in addition influenced by increased transport of warm oceanic air and reductions of Arctic sea ice.

[21] Acknowledgments. This work was carried out within the German Climate Research Program DEKLIM of the Federal Ministry for Education and Research (BMBF). The simulations have been performed at the German Climate Computing Center, Hamburg.

\section{References}

Berger, A. L. (1978), Long-term variations of daily insolation and Quaternary climate changes, J. Atmos. Sci., 35, 2362-2367.

Berger, A., and M. F. Loutre (2002), An exceptionally long interglacial ahead?, Science, 297, 1287-1288.

Guiot, J. (1990), Methodology of the last climatic cycle reconstruction in France from pollen data, Palaeogeogr. Palaeoecol., 80, 49-69.

Kühl, N., and T. Litt (2003), Quantitative time series reconstruction of Eemian temperature at three European sites using pollen data, Veg. Hist. Archaeobot., 12(4), 205-214.

Kühl, N., C. Gebhardt, T. Litt, and A. Hense (2002), Probability density functions as botanical-climatological transfer functions for climate reconstruction, Quat. Res., 58, 381-392.

Kukla, G. J., et al. (2002), Last interglacial climates, Quat. Res., 58, 2 13. 
Legutke, S., and R. Voss (1999), The Hamburg atmosphere-ocean coupled circulation model ECHO-G, Tech. Rep. 18, Dtsch. Klimarechenzent., Hamburg, Germany.

McAvaney, B. J., et al. (2001), Model evaluation, in Climate Change 2001: The Scientific Basis, edited by J. T. Houghton et al., pp. 471-523, Cambridge Univ. Press, New York.

Min, S.-K., S. Legutke, A. Hense, and W.-T. Kwon (2005), Internal variability in a 1000 -year control simulation with the coupled climate model ECHO-G, Tellus, Ser. A, in press.

Menke, B., and R. Tynni (1984), Das Eeminterglazial und das Weichselfrühglazial von Rederstall/Dithmarschen und ihre Bedeutung für die mitteleuropäische Jungpleistozän-Gliederung, Geol. Jahrb, Reihe A, 76, $3-120$.

Müller, H. (1974), Pollenanalytische Untersuchungen und Jahresschichtenzählung an der eem-zeitlichen Kieselgur von Bispingen/Luhe, Geol. Jahrb, Reihe A, 21, 149-169.

New, M. G., M. Hulme, and P. D. Jones (1999), Representing 20th century space-time climate variability, J. Clim., 12, 829-856.
Petit, J. R., et al. (1999), Climate and atmospheric history of the past 420,000 years from the Vostok ice core, Antarctica, Nature, 399, 429436.

Sinka, K. J., and T. C. Atkinson (1999), A mutual climatic range method for reconstructing palaeoclimate from plant remains, J. Geol. Soc. London, $156,381-396$.

Sowers, T. (2001), $\mathrm{N}_{2} \mathrm{O}$ record spanning the penultimate deglaciation from the Vostok ice core, J. Geophys. Res., 106(D23), 31,903-31,914.

Wunsch, C. (2004), Quantitative estimate of the Milankovitch-forced contribution to observed Quaternary climate change, Quat. Sci. Rev., 23, $1001-1012$.

U. Cubasch and F. Kaspar, Institut für Meteorologie, Freie Universität Berlin, Carl-Heinrich-Becker-Weg 6-10, D-12165 Berlin, Germany. (kaspar@dkrz.de)

N. Kühl and T. Litt, Institute for Paleontology, University of Bonn, Nussallee 8, D-53115 Bonn, Germany. 